session. In contributed papers there were discussions of seismicity related to hydraulic mining in New York state and seismicity associated with a complex of oil, water and gas at different levels under Lacq, France.

In seismicity related to fluid injection, fluid pressure is clearly the trigger and as with reservoirs, the pre-existing fractures and stresses are all-important and in general only become known if and when earthquakes occur. Pulling the trigger is not the best way to find out whether a gun is loaded; measurement of initial stress near future reservoirs and near oilfields where high-pressure injection is proposed could be a useful exercise for government agencies.

A session on instrumentation for observation of induced seismicity was led by a review by E. R. Kanasewich (University of Alberta), who made a strong case for introduction of digital recording systems employing miniaturised solid-state electronics and dedicated minicomputers. This triggered a brisk discussion in which the merits of many simple instruments were urged by others, particularly in adverse environments far from shop support.

The six review papers and over fifty contributed papers provoked lively and absorbing discussions and it is a matter of regret that more seismologists, and especially more engineers, did not attend. For those who did, the week seems to have been well spent.

\section{Growth hormone at Milan}

\section{from Mike Wallis}

The Third International Symposium on Growth Hormone and Related Peptides was held in Milan on September 17-20. Abstracts have been published (Ricerca Scientifica ed Educazione Permanente, 2, Suppl. 1) and the invited lectures will be published in full by Excerpta Medica in 1976.

Proterns come in families, and this conference covered all the members of the pituitary growth hormone family, including prolactin and placental lactogen. The ground covered was thus broad (over 160 papers) and attention here will be concentrated on growth hormone $(\mathrm{GH})$.

A topic which raised much discussion was the possibility that pituitary GH itself is in fact a prohormone. S. Ellis and R. E. Grindeland (NASA-Ames Research Centre, California) described studies on the nature of $\mathrm{GH}$ in human plasma, and concluded that the circulating form has enhanced biological activity and reduced immunological activity compared with $\mathrm{GH}$ extracted from pituitaries; purification of $\mathrm{GH}$ from plasma is underway. U. J. Lewis et al. (Scripps Clinic, La Jolla) have detected various forms of GH (apparently produced by limited proteolytic cleavage) with enhanced biological activities; these are obviously candidates for the 'activated' form which appears to circulate in the blood. M. A. Vodian and C. S. Nicoll (University of California) found that bioassay and immunoassay gave widely differing results for circulating $\mathrm{GH}$ in the rat (and for $\mathrm{GH}$ secreted by pituitaries incubated in vitro) although the two assays agree well when used to measure the $\mathrm{GH}$ content in the pituitary of resting, untreated rats.

The suggestion that $\mathrm{GH}$ is modified in vivo accords well with observations that active fragments can be produced by limited proteolysis of the hormone in vitro. C. $\mathrm{H}$. $\mathrm{Li}$ and $\mathrm{T}$. A. Bewley (University of California) and J. L. Kostyo et al. (Emory University) described the characterisation of peptides from plasmin digests of $\mathrm{GH}$ which retain biological activity in several different assay systems. L. Graf et al. (Research Institute for Pharmaceutical Chemistry, Budapest) described a similar approach using thrombin. Active fragments have also been synthesised chemically, as described by F. Chillemi et al. (University of Milan). How these studies on active fragments produced in vitro can be related to those produced in vivo is not yet clear. One attempt to make the link has been made by J. Bornstein (Monash University) who has isolated (from pituitaries) small peptides apparently derived from growth hormone. These have been synthesised chemically, and have been shown to be active in a range of pharmacological and biochemical test systems, but how they relate to the other work on $\mathrm{GH}$ fragments, or to the maior biological actions of $\mathrm{GH}$, remains uncertain.

Biosynthetic precursors of $\mathrm{GH}$ have been suggested on several occasions, and a paper by F. C. Bancroft (Columbia University) provided an elegant demonstration of the probable existence of such a precursor. Messenger RNA (from a line of pituitary tumour cells) was prepared and translated in a cell-free system from wheat germ. A major product possessed immunological and chemical resemblance to $\mathrm{GH}$, but was $20 \%$ larger than the normal hormone. It appears that the wheat germ system (unlike mammalian cell-free systems) lacks the enzymes which process the GH-precursor (pro-GH or perhaps pre-GH); a similar situation has been demonstrated for several other polypeptide hormones. The existence of a precursor was also proposed by $\mathbf{M}$. Wallis (University of Sussex) to explain the N-terminal heterogeneity seen in bovine $\mathrm{GH}$.

A major topic of discussion with regard to the biological actions of $\mathrm{GH}$ was the role of somatomedins $(\mathrm{GH}-$ dependent peptides found in serum). It is not yet clear whether these mediate all the actions of $\mathrm{GH}$, including growth promotion, or whether $\mathrm{GH}$ possesses some direct metabolic activity in addition to its role in promoting somatomedin production. Exciting progress in the somatomedin field was described, though it is unfortunate that some work is shrouded in secrecy as a result of the interest of the pharmaceutical industry. At least three somatomedins have now been recognised, distinguished by their relative potencies in different assay systems. Isolation and characterisation of somatomedins A and $\mathbf{B}$ was described by L. Frykland and $\mathrm{H}$. Sievertsson (AB KABI, Stockholm). They are moderate-sized peptides, structurally quite different, and neither is a fragment of GH. K. Hall and $\mathrm{K}$. Takano (Karolinska Hospital, Stockholm) described their radioreceptor assays and immunoassays for somatomedins A and B. Levels in normal human serum are quite high (about $2 \mu \mathrm{g} \mathrm{ml}^{-1}$ for somatomedin $\mathrm{A}$, $10 \mu \mathrm{g} \mathrm{ml}^{-1}$ for somatomedin B). As expected, levels rise in acromegaly and fall in hypopituitary dwarfism. The somatomedins are not completely absent in the latter, however, so these factors are perhaps only partially $\mathrm{GH}$ dependent. L. E. Underwood et al. (University of North Carolina) described work on somatomedin C (a moderate-sized, basic peptide) and showed that receptors for this occur in most tissues.

Lactogenic hormones can be mentioned only briefly here. R. E. Fellows (Duke University) has characterised ruminant placental lactogens and preliminary structural studies suggest that, as has been predicted, these differ substantially from human placental lactogen.

The idea of holding a conference in which all members of the $\mathrm{GH}$-prolactin family of proteins were considered was an excellent one. Although the growth hormones and lactogenic hormones are clearly related structurally, and must have had a common evolutionary origin, little resemblance has been detected at the biological level. It seems likely that structural resemblances are paralleled by resemblances in biochemical mode of action but these have not yet been clearly established. Perhaps this will be one of the themes of the 4th International Symposium on $\mathrm{GH}$ in four years' time. 